\title{
Violência: conceito e vivência entre acadêmicos da área da saúde
}

Rosiléia Rosa ${ }^{1}$

Antonio Fernando Boing ${ }^{2}$

Lilia Blima Schraiber ${ }^{3}$

Elza Berger Salema Coelho ${ }^{4}$

ROSA, R. et al. Violence: concept and experience among health sciences undergraduate students. Interface - Comunic., Saude, Educ., v.14, n.32, p.81-90, jan./mar. 2010.

The investigation analyzed the concept and experience of violence among the last year academics of the courses of graduation in nursing, medicine and dentistry of the Federal University of Santa Catarina. It was an exploratory descriptive research with quali-quantitative boarding, developed with 175 academics. The proposal was identify what are the academics understanding about violence, which are their personal experiences on the subject and what kind of boarding was given to this question during the undergraduate course. The violence definitions are hardly related to a technique sight and prioritize the suffered physical damages. Faced with a violence situation the students had reproduced the feelings of fear, impotence, anger and indignation; they did not react when witnessing such acts and showed that the health professional does not identify situations of violence when providing superficial assistance to victims; concluding, they consider that the issue is not sufficiently discussed during the academic course.

Keywords: Violence. Health. Higher education. Professional formation.
Trata-se de uma investigação sobre conceitos e vivências sobre violência de acadêmicos do último ano dos cursos de graduação em Enfermagem, Medicina e Odontologia da Universidade Federal de Santa Catarina. Caracterizada como uma pesquisa descritiva exploratória com abordagem qualiquantitativa com 175 acadêmicos, a proposta foi compreender qual a definição de violência para os acadêmicos, quais suas vivências sobre o tema e qual a inserção que o tema violência teve durante a formação acadêmica. As definições sobre violência estiveram fortemente relacionadas a uma visão técnica e priorizaram os danos físicos sofridos pelas pessoas agredidas. Diante de uma situação de violência os acadêmicos reproduziram sentimentos de medo, impotência, raiva e indignação e não reagiram ao presenciar tais atos; evidenciaram que o profissional de saúde não identifica situações de violência quando presta assistência de forma superficial às vítimas; e que a formação acadêmica não discute o tema suficientemente.

Palavras-chave: Violência. Saúde. Ensino superior. Formação profissional.

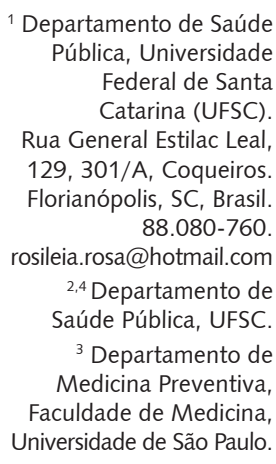




\section{Introdução}

Violência, para a Organização Mundial de Saúde, caracteriza-se pelo uso intencional da força física ou do poder, real ou em ameaça, contra si próprio, contra outra pessoa, ou contra um grupo ou uma comunidade, que resulte ou tenha a possibilidade de resultar em lesão, morte, dano psicológico, deficiência de desenvolvimento ou privação (Krug et al., 2002).

Pelo elevado número de vítimas que acarreta e pela magnitude de sequelas orgânicas e emocionais que produz, a violência configura-se no início do século XXI como grave problema de saúde pública em diversos países. Em todo o mundo, a cada ano mais de um milhão de pessoas perdem a vida e muitas outras sofrem ferimentos não fatais resultantes de autoagressões, de agressões interpessoais ou de violência coletiva, estimando-se que a violência seja uma das principais causas de morte de pessoas entre 15 e 44 anos em todo o mundo (Dahlberg, Krug, 2002).

No Brasil, desde o ano 2000 as causas externas ocupam a terceira posição na causa de óbitos no país, além de englobarem expressiva quantidade de internações hospitalares (Brasil, 2007; Jorge, Koizumi, 2004). Num recorte para as agressões interpessoais, destacam-se os atos de violência impetrados no âmbito doméstico e, em específico, contra mulheres, idosos e crianças. Estudos conduzidos em serviços de saúde sobre a violência contra a mulher demonstraram sua elevada prevalência, variando de $30 \%$ a $60 \%$ a proporção de mulheres que relataram terem sido vítimas de violência doméstica de natureza emocional, física ou sexual ao menos uma vez na vida (Schraiber et al., 2007; Kronbauer, Meneghel, 2005; Marinheiro, Vieira, Souza, 2006); Silva, 2003; Schraiber et al., 2002). Já em relação à infância, no estado do Rio de Janeiro verificou-se que no início da década de 1990 cerca de $70 \%$ dos homicídios de crianças de zero a 11 anos foram perpetrados pela própria família (Soares, 1997). A violência contra o idoso também é intensa e disseminada nas sociedades. Minayo (2003) destacou que, apesar de muitas vezes naturalizados na sociedade e nas relações familiares, os casos de abusos físicos, sexuais, psicológicos e financeiros contra idosos são abrangentes no país.

Diante desse contexto de alta magnitude da violência e a alta mortalidade por causas violentas, vários estudos têm destacado a importância da atuação dos serviços de saúde no reconhecimento e no enfrentamento desse problema, em particular nos casos de violência doméstica (Schraiber et al., 2005; García-Moreno, 2002). No entanto, apesar de os serviços de saúde representarem um campo de assistência e acolhimento de vítimas de violência, os usuários deparam-se com respostas inadequadas dos profissionais de saúde, barreiras do próprio serviço para que o usuário exponha sua situação e a não confiança no profissional para relatar o problema enfrentado (Robinson, Spilsbury, 2008). Historicamente, o setor saúde olhou para o fenômeno da violência enquanto expectador ou contador de eventos (Minayo, Souza, 1999) e atualmente os profissionais de saúde acabam se confrontando com esta realidade em sua prática cotidiana, porém nem sempre preparados para assumir tais atribuições (Gomes, 2002).

Uma das dificuldades do profissional de saúde pode estar relacionada ao fato de a maior parte dos processos de formação estar fundamentada em um modelo disciplinar centrado na racionalidade biomédica, remetendo alunos e professores a uma redução drástica dos processos de saúde-doença à sua dimensão biológica e dos sujeitos/pacientes à sua doença (Almeida, Feuerwerker, Llanos, 1999). Além disso, os currículos das universidades brasileiras, salvo experiências pontuais, têm demonstrado inadequações de conteúdo e de práticas pedagógicas para o exercício de atividades que envolvam a pluralidade das necessidades do sistema de saúde (Brasil, 2006), inclusive na temática da violência.

Diante dessa realidade, e considerando-se que a formação universitária se refletirá na assistência prestada e no acolhimento da população usuária dos serviços de saúde, o presente estudo objetivou investigar os conceitos sobre violência presentes entre acadêmicos dos cursos de Enfermagem, Medicina e Odontologia, quais suas vivências pessoais sobre o tema e que abordagem foi dada a essa questão durante a formação acadêmica nos três cursos. 


\section{Metodologia}

Trata-se de um estudo descritivo exploratório com abordagem qualiquantitativa. Empregaram-se questionários autoaplicáveis contendo questões abertas e fechadas, permitindo, assim, aproximação tanto qualitativa como quantitativa das respostas dos sujeitos entrevistados. O questionário construído para o presente estudo foi estruturado em três partes. A primeira englobou o perfil dos entrevistados (curso e fase de graduação, sexo, idade e estado civil); a segunda tratou das definições dos acadêmicos sobre violência e suas vivências com episódios de violência; na terceira parte, as perguntas estiveram voltadas a compreender que abordagem foi dada à violência durante a formação acadêmica nos três cursos pesquisados.

Os sujeitos entrevistados foram acadêmicos regularmente matriculados no último ano dos cursos de Enfermagem, Medicina e Odontologia da Universidade Federal de Santa Catarina. Para solicitar autorização da pesquisa, os autores realizaram encontros com as coordenações e professores dos cursos envolvidos, tendo tal momento também a finalidade de apresentar os objetivos e procedimentos do presente estudo. Os dados foram coletados em sala de aula durante períodos liberados por professores no decorrer das disciplinas específicas do último ano de cada curso. A participação dos acadêmicos foi voluntária e o convite foi realizado na hora da aplicação dos questionários, cujo preenchimento durou, em média, cinquenta minutos. Dos 237 acadêmicos matriculados, $175(73,8 \%)$ participaram do estudo, sendo 41 do curso de Enfermagem, 65 de Medicina e 69 de Odontologia.

Nesses cursos, o último ano de faculdade tem grande carga horária, ou até mesmo a sua totalidade, destinada a estágios com atividades práticas. Como a universidade permite que as mesmas sejam realizadas em outras instituições nacionais ou internacionais, parte das perdas foi devida a essa saída temporária de acadêmicos da universidade pesquisada. Os demais não foram entrevistados por terem faltado às aulas em que os dados foram coletados. Todos os acadêmicos que estavam presentes nas salas de aula durante a pesquisa concordaram em participar dela.

Os dados foram analisados a partir de eixos de discussão dos relatos dos acadêmicos, abrangendo elementos e aspectos com características comuns ou que se relacionaram entre si, segundo análise de conteúdo proposta por Bardin (1979). Definiram-se dois eixos de análise: Eixo 1: A violência enquanto conceito entre os acadêmicos - que apresenta as conceituações e os tipos de violência evidenciados pelos mesmos - e Eixo 2: A invisibilidade da violência - que se constitui por aspectos relacionados à formação acadêmica e à atuação do profissional de saúde. Os dados quantitativos foram registrados no programa EpiData 3.1, obtendo-se as medidas de frequência e de dispersão.

No intuito de garantir o anonimato dos sujeitos da pesquisa, os relatos foram identificados pelas abreviaturas $E$ (acadêmicos de enfermagem), $M$ (medicina) e $O$ (odontologia), seguidas pela fase do curso. Os pesquisadores, inclusive a que aplicou os questionários, não possuíam vínculo com os acadêmicos, tampouco havia conflitos de interesses envolvidos no estudo.

A pesquisa foi aprovada pelo Comitê de Ética em Pesquisa da Universidade Federal de Santa Catarina sob o parecer n²77/2007, atendendo à Resolução 196/96 do Conselho Nacional de Saúde.

\section{Resultados e discussão}

\section{Eixo 1: A violência enquanto conceito entre os acadêmicos}

Dos acadêmicos entrevistados, $64 \%$ eram do sexo feminino (cujas idades variaram de vinte a 32 anos) e $36 \%$ do sexo masculino (entre 22 e 35 anos). Quanto ao estado civil, 90,9\% eram solteiros e $9,1 \%$ viviam com parceiros.

Quando questionados sobre o que é violência, os acadêmicos relataram que ela se configura sobretudo por atos de violência física, psicológica ou que infrinjam a liberdade de alguém. A maioria dos pesquisados relatou que violência pode ser a junção dessas expressões, no entanto, a violência 
física foi a que apareceu com mais frequência (56,5\%), seguida da psicológica (28,0\%). A violência sexual foi a menos referenciada, sendo citada em apenas 4,5\% das respostas.

Evidenciou-se, assim, que, para mais da metade dos entrevistados, os conceitos sobre violência estão relacionadas aos danos físicos provocados à vítima, como nos exemplos: "é uma maneira de agredir fisicamente; qualquer tipo de agressão à integridade física" (O-8af; $M-11^{\text {a }}$ ).

O conceito de violência lembrado como ato de violência psicológica foi compreendido como xingamento que gera sofrimento; pressão; atos de desprezo (E-7af; M-11af; O-9af). Outra conceituação relevante, que alcançou $20,5 \%$ das respostas, não foi classificada nem como violência física nem psicológica, mas como ato que possa "infringir a liberdade do próximo; ultrapassar os limites, não respeitar a vida, as escolhas do outro; tudo o que fere nossos direitos" ( $M-11^{\mathrm{a}} \mathrm{f} ; \mathrm{M}-11^{\mathrm{a}} \mathrm{f} ; \mathrm{E}-\mathrm{7}^{\mathrm{a}} \mathrm{f}$ ). Esses últimos relatos vão ao encontro do que afirma Araújo (2002) quando aponta que, se tomamos a liberdade como uma capacidade e um direito fundamental do ser humano, podemos dizer que a violência é uma violação do direito de liberdade, do direito de ser sujeito constituinte da própria história.

Quando solicitado que identificassem conceitos para violência física, psicológica e sexual, a violência física foi compreendida como "agressão física, lesão corporal ou contato físico" por 75\% dos acadêmicos; a violência psicológica foi percebida enquanto "danos à mente e emocionais representadas por atos de discriminação, rejeição, humilhação, constrangimento, ameaça ou pressão" para $48,5 \%$ deles; e a violência sexual foi reconhecida como "forçar relação sexual" para $32 \%$ dos pesquisados. O estupro foi lembrado como violência sexual somente por 17,0\% no curso de Enfermagem, $14,5 \%$ no de Odontologia e 10,7\% no de Medicina. Considerando que as mulheres são frequentemente as maiores vítimas de violência sexual e que $64 \%$ dos pesquisados eram do sexo feminino, surpreende os baixos índices de reconhecimento deste tipo de violência, como ainda a referência sobre o estupro.

O Relatório Mundial sobre Saúde e Violência (Krug, 2002) definiu que a violência sexual compreende uma variedade de atos ou de tentativas de relação sexual sob coação ou fisicamente forçada, podendo ser no casamento ou em outros relacionamentos (Cavalcanti, Gomes, Minayo, 2006), sendo lembrada no casamento por apenas um entrevistado que definiu violência sexual como "forçar relação mesmo sendo casados, ter qualquer aproximação dita sexual [...]" (E-7a f).

Entre os relatos sobre as definições de violência, chama a atenção os que afirmam que: " $[\ldots .$. violência serve para danos maiores ou violência física que quase sempre considero violência; penso mais na violência física, que acho mais marcante e mais importante... outros tipos de violência ficariam muito abrangentes e menos importantes" ( $\left.\mathrm{M}-12^{\mathrm{a}} \mathrm{f} ; \mathrm{O}-9^{\mathrm{a}} \mathrm{f}\right)$. Diante da afirmação, cabe questionar: é possível considerar que outros tipos de violência sejam menos importantes, principalmente enquanto futuros profissionais da área da saúde? Como reconhecer a violência no serviço de saúde quando o olhar pode estar direcionado somente para a violência física? É provável que os acadêmicos entrevistados vivenciarão contextos de violência nas suas atividades profissionais e se considerarem que ela existe quando a vítima traz consigo apenas danos físicos, outras formas de violência podem ser subestimadas, reforçando-se assim a importância desta temática nas discussões acadêmicas. A predominância da violência enquanto ação física pode, ainda, conforme apontado por Guimarães e Campos (2007), destituí-la do lugar da excepcionalidade para tornar-se uma marca do cotidiano, apresentando-se como "comuns" ou "banais".

Sobre as vivências pessoais sobre violência e o que sentiram, a maior parte dos acadêmicos $(74,8 \%)$ relatou que já vivenciou situações de violência. Os sentimentos predominantes nos relatos foram medo e impotência, conforme relatos a seguir: "tive uma sensação de impotência; senti medo; impotência por não poder fazer nada e medo" (M-11 af; O-8af; E-8af). Essa sensação de incapacidade foi evidenciada no estudo de Schraiber et al. (2003), apresentando profissionais que atenderam casos de violência doméstica e sentiram impotência para lidar com os casos.

Sentimentos contraditórios diante da violência também foram relatados, como "medo e revolta, indignação e compaixão, impotência e revolta, raiva do agressor e sentimento de vingança" (O-9af; M-12af; E-8 af). O desejo de revidar o ato de violência também foi encontrado por Schraiber et al. (2005), onde a vontade de revanche contra o agressor esteve presente. Mesmo diante desses 
sentimentos que sugerem atitude, os acadêmicos não relataram providências frente à violência experimentada, permanecendo na "vontade de reação". Sabe-se que a fragilidade nestas situações é inegável e nem sempre o auxílio é a primeira atitude. No entanto, torna-se oportuno pensar se tais dificuldades no enfrentamento do vivenciado podem refletir nas ações enquanto profissional e, segundo apontado por Dal'ri (2007), representar atitudes cúmplices ou ocultadoras da violência.

Chama a atenção que os acadêmicos que vivenciaram situações de violência não diferiram em suas opiniões e definições dos demais entrevistados. Em decorrência desse aspecto, deve-se assinalar a distância que se registra entre pessoal e profissional, ainda que na presente investigação esta questão não tenha sido aprofundada, merecendo pesquisas futuras.

\section{Eixo 2 - A invisibilidade da violência}

Para os acadêmicos, a dificuldade do profissional de saúde em identificar vítimas de violência no desempenho de suas atividades está vinculada a ele mesmo $(87,4 \%)$, ao paciente $(33,1 \%)$ e à formação acadêmica $(22,8 \%)$ como os principais fatores que contribuem para a invisibilidade da violência (os acadêmicos poderiam se referir a mais de uma opção), reiterando nesses aspectos o estudo de Kiss (2004). Foi referenciada a invisibilidade da violência perante o profissional, destacando-se o distanciamento entre profissional e paciente $(44,5 \%)$ e a ausência da concepção de integralidade na assistência pelo profissional (37,7\%). Quanto ao paciente, justificaram que eles escondem os fatos quando estes estão relacionados à violência $(26,8 \%)$ e que têm vergonha da violência sofrida $(5,7 \%)$. Sobre a formação acadêmica, destacaram que as informações sobre violência são insuficientes na universidade $(15,4 \%)$ e que o tema é abordado superficialmente $(7,4 \%)$.

As dificuldades relacionadas ao profissional na identificação das vítimas de violência, para os acadêmicos, se dão pela falta de sensibilidade e escuta que poderiam contribuir para a percepção do fenômeno e apontar possibilidades de intervenção neste processo. Para Maldonado (1998), ouvir com atenção, consideração e sensibilidade amplia a capacidade de escuta sensível, sendo possível entender o que está por trás das palavras, na linguagem do corpo e dos atos. As falas, a seguir, evidenciam a afirmação: "a falta de sensibilidade, de ouvir o paciente e vê-lo como uma pessoa; o pouco interesse do profissional em dar mais tempo para ouvir o paciente" (E-7af; O-9af). As afirmações apresentam o distanciamento do profissional diante dos problemas sociais a que a população está exposta, contribuindo para que atos de violência não sejam percebidos e, conforme afirma Morin (2004), oportunizar a invisibilidade dos problemas, impedindo de se ver a realidade.

Os acadêmicos apontaram, ainda, que "na maioria das vezes o paciente não é tratado como um todo, ou seja, o profissional só se preocupa com a sua especialidade. Onde o dentista só se importa com a boca; os profissionais de saúde, em sua grande maioria, olham e cuidam da patologia e não do paciente no seu todo" (O-8 f; E-7 ${ }^{\mathrm{a}}$ f). Schraiber et al. (2003), em estudo sobre a violência contra a mulher, apontaram que há ausência de linguagem apropriada e comum aos profissionais para abordálas, posto que eles dialogam somente na linguagem da doença, o que torna a comunicação dos fatos ainda mais difícil. Kaplan (2005) reforçou que é preciso usar habilidade conceitual para se ver o todo, o significado em si. Desta forma, estando o olhar do profissional direcionado unicamente para a queixa, corre-se o risco de não se analisarem outros agravantes.

Foi reconhecida por parte dos entrevistados a importância do diálogo na relação entre profissional de saúde e paciente, uma vez que a vítima de violência não traz consigo somente o ferimento físico, mas também a angústia, o medo, o constrangimento. Neste sentido, a necessidade do "olhar para o todo", termo recorrentemente citado pelos pesquisados, reforça que o profissional não deve mediar seu atendimento pautado no distanciamento e na frieza emocional, mas sim que tenha a capacidade de colocar-se no lugar da vítima e percebê-la integralmente, agindo em prol da sua saúde.

Ao se colocarem na posição de profissionais, os acadêmicos afirmaram que "a classe médica, infelizmente, não faz uma história adequada do paciente. A pressa, a falta de vontade da nossa parte, principalmente em atendimentos dos serviços públicos, impede de nos aprofundarmos nas queixas do paciente; muitas vezes nós profissionais não questionamos" (M-11af; $M-11^{\mathrm{a} f}$ ). Nestes relatos, 
os acadêmicos se posicionaram como profissionais de saúde, sugerindo que já exercem as mesmas condutas que criticam, e que, dessa forma, poderão ser os perpetuadores do ocultamento de situações de violência, mesmo diante da consciência de que esses atos não são os esperados do profissional de saúde. No modelo centrado apenas na doença, Sucupira (2007) aponta que o atendimento prestado resume-se a dar uma resposta imediata, visando dispensar o mais depressa possível a clientela em função do acúmulo de demanda. Assim, quando o foco passa a ser a doença e não o indivíduo, as chances para que o paciente retorne aos serviços aumentam, assim como a demanda dos mesmos.

Os problemas relacionados ao paciente referem-se, na visão dos acadêmicos, ao fato de que este "mascara, esconde e mente quando questionado; talvez porque no caso de crianças os pais omitam e inventam histórias bem boladas; porque as vítimas de violência escondem isto da sociedade, muitas vezes por medo da violência ocorrer novamente" (E-7af; M-11ªf; O-9af). Essas reações, quando existentes, podem estar relacionadas com a atitude do profissional de saúde, quando este não estabelece a comunicação necessária, o vínculo devido e centraliza suas ações na doença, ou conforme apontado pelos acadêmicos, as mantêm ancoradas em especialidades. Nestes casos, o diálogo com os pacientes é pautado predominantemente pela exploração dos sinais, sintomas e manifestações laboratoriais dos agravos; realiza-se uma prática repetitiva, sem dar conta das singularidades inerentes (Coelho Filho, 2007).

Neste sentido, a pessoa que sofreu violência não passaria, necessariamente, a esconder do profissional de saúde que foi vítima de violência, mas sim, demonstraria "constrangimento, dificuldade para se expressar" (M-11 a f). Atualmente, demandam aos consultórios novas questões da sociedade, como a violência, o alcoolismo, questões relacionadas ao casamento, ao emprego, às dificuldades na vida escolar, entre outras, exigindo do profissional habilidade como escuta e comunicação, que vão além dos conhecimentos estritamente biomédicos (Sucupira, 2007). Nestes casos, o profissional precisa desenvolver uma forma eficaz para se aproximar da pessoa agredida, criando um clima propício para que essa dificuldade de expressão possa ser superada.

Outro fator a ser considerado, segundo os acadêmicos, é que "os violentados não falam, muito menos para pessoas estranhas; é quase impossível diagnosticar um tipo de violência que quase não causou dano físico e também quando o mesmo não abre a situação de forma sincera" (E-8 ${ }^{a}$ f; M-11 af). Para Gomes (1998), de fato em alguns casos o profissional de saúde pode ter maiores dificuldades para abertura, interferindo numa melhor atuação do mesmo, tornando mais difícil a interação no espaço privado da vítima, porém, a falta de informações passa a ser tão violenta quanto os crimes praticados. Chama a atenção, por outro lado, que os entrevistados não comentam o fato de os profissionais raramente investigarem situações de violência e esperam que o paciente seja um interlocutor ativo. Isto contrasta, por exemplo, com a anamnese clínica e seu interrogatório, quando os profissionais tendem a ser ativos na busca dos diagnósticos, e, de outro lado, contrastam e contradizem seus depoimentos de quão difícil é, para a vítima, por medo, culpa ou vergonha, ser ativa para relatar a violência sofrida.

A invisibilidade da violência relacionada com a formação refere-se a "ser pouco discutida no meio acadêmico; o estudante depende de sua sensibilidade e não de sua formação (incompleta) para fazer o diagnóstico; há despreparo na graduação, não é um assunto muito discutido" (O-9a f; $M-11^{\mathrm{a}} \mathrm{f}_{\text {; }}$ $\mathrm{E}-7^{\mathrm{a}} \mathrm{f}$ ). Sobre os momentos em que o tema violência foi abordado durante o curso de graduação, $73,2 \%$ dos acadêmicos da Enfermagem referiram a disciplina "Sociedade, Saúde e Violência", ministrada na quinta fase do curso; $98,5 \%$ da Medicina mencionaram ter estudado o tema em mais de uma disciplina, sendo majoritariamente em Pediatria (69,2\%) e Medicina Legal (29,2\%). Situação diferenciada apontaram os acadêmicos da Odontologia, sendo que $65,2 \%$ responderam que o tema violência jamais foi abordado; os demais referiram predominantemente as disciplinas de Cirurgia e Traumatologia e Endodontia.

No entanto, quandoperguntado sobre a necessidade de abordar a violência na formação acadêmica, a contra a criança foi apontada por $(66,3 \%)$ dos acadêmicos, como assunto de maior necessidade e urgência, seguida da contra a mulher $(14,3 \%)$, o idoso $(6,8 \%)$ e o adolescente $(2,8 \%)$. Estes dados apontam, para os acadêmicos, a necessidade da abordagem do tema na formação e a vulnerabilidade destes públicos em contexto de violência, reconhecem ainda, em especial, a fragilidade 
da criança, enquanto vítima de violência. Mesmo quando o tema violência esteve presente na formação acadêmica, as informações sugerem ter sido esporádica e superficial, fazendo com que os profissionais sintam-se despreparados para abordar esse contexto.

Mesmo com a pouca inserção do tema violência nos seus currículos, quando perguntados sobre qual profissional estaria mais preparado para lidar com situações de violência, os acadêmicos de Odontologia e de Medicina citaram predominantemente o médico, seguido do enfermeiro. Para a Enfermagem, são os enfermeiros, seguidos pelos médicos, os mais preparados. Ainda assim, $100 \%$ da Enfermagem, 98,5\% da Medicina e 92,8\% da Odontologia acreditam que podem auxiliar as vítimas de violência. Relativamente aos que consideram o médico o principal profissional envolvido com a violência, pode-se afirmar que nesta visão os acadêmicos reforçam a pesquisa de Marques (2007), em que a centralidade do profissional médico evidencia que o tratamento dos usuários hospitalizados por agressão segue as especialidades médicas como único critério de indicação para a unidade de internação.

Quando perguntados quais seriam as ações dos acadêmicos diante de uma possível vítima de violência, foram apontados procedimentos de orientações e encaminhamentos dos casos. As orientações estariam relacionadas ao diálogo que instrui o paciente, aconselha e educa sobre o tema $(82,3 \%)$; e os encaminhamentos seriam para a troca de auxílio com outros profissionais, buscando, sobretudo, apoio psicológico, realizações do diagnóstico por alguma especialidade médica e tratamento específico $(17,7 \%)$. A importância destes encaminhamentos é justificada por: "diariamente temos contato com pessoas que sofreram algum tipo de violência. Devemos saber agir corretamente nesses casos. Também quando desconfiamos de que alguma criança seja vítima de

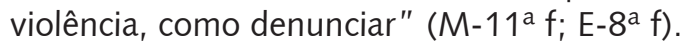

Já os encaminhamentos a serem dados para as vítimas de violência, segundo os entrevistados, deveriam, primeiramente ser para a polícia/delegacia $(48,0 \%)$, seguida do hospital $(26,8 \%)$, centros de saúde $(10,8 \%)$ e serviço social $(4,5 \%)$. Ficou evidente que no currículo não se discute sobre protocolos de atendimento às vítimas de violência, pois, conforme aponta Njaine et al. (1997), o serviço de saúde não detecta os casos e, quando o faz, não encaminha ou não sabe que atitude adotar, ou, ainda, prefere ignorar seu compromisso e age negligentemente em relação à violência. $\mathrm{Da}$ mesma forma, Ferreira e Schramm (2000), apontaram a dificuldade dos profissionais ao confrontaremse com alguns procedimentos específicos, como a notificação dos casos ao sistema legal. Além disso, esses achados reforçam o apontado por Krug et al. (2002), de que a violência ainda é vista, sobretudo, como questão de justiça ou de segurança, mas não necessariamente de saúde.

A compreensão da violência enquanto problema de saúde precisa contar com o aporte da universidade, uma vez que o espaço da formação contribui para o direcionamento das ações profissionais, que precisam estar ancoradas nos problemas vividos pela sociedade. Além disso, cabe lembrar que a área da saúde deve aprofundar as questões e as formas de atuação na promoção da saúde e que a violência deve ser um dos temas-chave nas discussões sobre integralidade.

O presente estudo apresentou como limitação o fato de descrever conceitos e vivências sobre violência relativas ao universo de apenas três cursos de graduação de uma universidade do sul do Brasil, prejudicando generalizações. O questionário autoaplicável foi construído e aplicado de maneira a permitir o posicionamento dos sujeitos de pesquisa sem constrangimento, e novas pesquisas com outras abordagens metodológicas - como grupos focais, por exemplo - são importantes para se aprofundarem os resultados oriundos do presente estudo. A inexistência de qualquer relação de dependência ou vínculo dos graduandos em relação aos pesquisadores também contribuiu para a qualidade dos dados coletados.

\section{Considerações finais}

Os acadêmicos de Enfermagem, Medicina e Odontologia, em sua maioria, já vivenciaram alguma situação de violência, porém as definições que possuem sobre o tema parecem não incorporar essa vivência, mas se ancoram em abordagens técnicas, em que os danos físicos são priorizados enquanto 
violência. Sentimentos de reação, como a raiva e a indignação, foram evidenciados, no entanto, em nenhuma situação os acadêmicos mostraram outras formas de lidar com a violência, expressando imobilidade diante dela. Ainda assim, esperam que os pacientes atuem de modo bem diverso, sendo ativos na procura de ajuda.

Mesmo que reconheçam a necessidade de uma abordagem integral por parte dos pacientes, enquanto ideal de prática futura, ao arrolarem as dificuldades no reconhecimento de situações de violência por profissionais, não conseguem avançar nessa proposição de integralidade, também se atendo a questões segmentadas, com destaque sempre à dimensão de uma competência mais técnica para poderem agir ou dependente da iniciativa dos pacientes, e não de suas relações com eles.

É preciso que a violência seja objeto de estudo em muitas interfaces científicas e objeto de discussão permanente por parte da sociedade para que se definam programas e políticas públicas adequadas e eficazes para o seu enfrentamento, assim como a elaboração de propostas e estratégias de ensino voltadas para as diversas expressões concretas da violência e seus diferentes contextos.

\section{Colaboradores}

A autora Rosiléia Rosa trabalhou na concepção, análise, interpretação dos dados e redação final do texto. Elza Berger Salema Coelho trabalhou na concepção, supervisão geral e redação final do texto. Antonio Fernando Boing trabalhou na metodologia, revisão crítica e redação final do texto. E Lilia Blima Schraiber trabalhou na revisão crítica e redação final do manuscrito.

\section{Referências}

ALMEIDA, M.; FEUERWERKER, L.; LLANOS, M. (Orgs.). A educação dos profissionais de saúde na América Latina: teoria e prática de um movimento de mudança. São Paulo: Hucitec, 1999.

ARAÚJO, M.F. Violência e abuso sexual na família. Psicol. Estud., v.7, n.2, p.3-11, 2002.

BARDIN, L. Análise de conteúdo. Lisboa: Edições 70, 1977.

BRASIL. Ministério da Saúde. Sistema de informações sobre mortalidade. Disponível em: <http://tabnet.datasus.gov.br/cgi/deftohtm.exe?sim/cnv/obtuf.def>. Acesso em: 20 maio 2007.

. Ministério da Saúde. Secretaria de Gestão do Trabalho e da Educação na Saúde. Dinâmica das graduações em Saúde no Brasil: subsídios para uma política de recursos humanos. Brasília: Ministério da Saúde, 2006.

CAVALCANTI, L.F.; GOMES, R.; MINAYO, M.C.S. Representações sociais de profissionais de saúde sobre violência sexual contra a mulher: estudo em três maternidades públicas municipais do Rio de Janeiro, Brasil. Cad. Saude Publica, v.22, n.1, p.31-9, 2006.

COELHO FILHO, J.M. Relação médico-paciente: a essência perdida. Interface Comunic., Saude, Educ., v.11, n.23, p.631-3, 2007.

DAHLBERG, L.L.; KRUG, E.G. Violence: a global public health problem. World Report on Violence and Health. Geneve: World Health Organization, 2002.

DAL'RI, M. Representações sociais de profissionais de saúde sobre a violência contra a mulher. 2007. Dissertação (Mestrado) - Universidade Federal de Santa Catarina, Florianópolis. 2007.

FERREIRA, A.L.; SCHRAMM, F.R. Implicações éticas da violência doméstica contra a criança para profissionais de saúde. Rev. Saude Publica, v.34, n.6, p.659-65, 2000. 
GARCÍA-MORENO, C. Dilemmas and opportunities for an appropriate health-service response to violence against women. Lancet, v.35, n.9316, p.1509-14, 2002.

GOMES, R. et al. A abordagem dos maus-tratos contra a criança e o adolescente em uma unidade pública de saúde. Cienc. Saude Colet., v.7, n.2, p.275-83, 2002.

GOMES, R. Da denúncia à impunidade: um estudo sobre a morbi-mortalidade de crianças vítimas de violência. Cad. Saude Publica, v.14, n.2, p.301-11, 1998.

GUIMARÃES, S.P.; CAMPOS, P.H.F. Norma social violenta: um estudo da representação social da violência em adolescentes. Psicol.: Reflex. Crit., v.20, n.2, p.188-96, 2007.

JORGE, M.H.P.M.; KOIZUMI, M.S. Gastos governamentais do SUS com internações hospitalares por causas externas: análise no Estado de São Paulo, 2000. Rev. Bras. Epidemiol., v.7, n.2, p.228-38, 2004.

KAPLAN, A. O processo social e o profissional de desenvolvimento: artistas do invisível. São Paulo: Instituto Fonte para o Desenvolvimento Social/Editora Fundação Peirópolis, 2005.

KISS, L.B. Temas médico-sociais e a intervenção em saúde: a violência contra mulheres no discurso dos profissionais. 2004. Dissertação (Mestrado) - Faculdade de Medicina, Universidade de São Paulo, São Paulo. 2004.

KRONBAUER, J.F.D.; MENEGHEL, S.N. Perfil da violência de gênero perpetrada por companheiro. Rev. Saude Publica, v.5, n.39, p.695-701, 2005.

KRUG, E.G. et al. World report on violence and health. Geneva: World Health Organization, 2002.

MALDONADO, M.T. Caminos de la prevención de la violencia domestica y escolar: construyendo la paz. Adolesc. Latinoam, v.1, n.2, p.111-7, 1998.

MARINHEIRO, A.L.V.; VIEIRA, E.M.; SOUZA, L. Prevalência da violência contra a mulher usuária de serviço de saúde. Rev. Saude Publica, v.4, n.40, p.604-10, 2006.

MARQUES, G.Q. et al. As práticas e o cotidiano de profissionais em serviços públicos de saúde, na ótica de estudos acadêmicos. Online Braz. J. Nurs., v.6, n.2, p.4-5, 2007.

MINAYO, M.C.S. Violência contra idosos: relevância para um velho problema. Cad. Saude Publica, v.19, n.3, p.783-91, 2003.

MINAYO, M.C.S.; SOUZA, E.R. É possível prevenir a violência? Reflexões a partir do campo da saúde pública. Cienc. Saude Colet., v.4, n.1, p.7-23, 1999.

MORIN, E. Os sete saberes necessários à educação do futuro. São Paulo: Cortez, 2004.

NJAINE, K. et al. A produção da (des)informação sobre violência: análise de uma prática discriminatória. Cad. Saude Publica, v.14, n.3, p.405-14, 1997.

ROBINSON L.; SPILSBURY, K. Systematic review of the perceptions and experiences of accessing health services by adult victims of domestic violence. Health Soc. Care Commun., v.16, n.1, p.16-30, 2008.

SCHRAIBER, L.B. et al. Violência contra a mulher entre usuárias de serviços básicos de saúde da rede pública da grande São Paulo. Rev. Saude Publica, v.41, n.3, p.359-67, 2007.

Violência dói e não é direito: a violência contra a mulher, a saúde e os direitos humanos. São Paulo: Ed. Unesp, 2005.

Violência vivida: a dor que não tem nome. Interface - Comunic., Saude, Educ., v.7, n.12, p.41-54, 2003.

Violência contra a mulher: estudo em uma unidade de atenção primária à saúde. Rev. Saude Publica, v.36, n.4, p.470-7, 2002. 
SILVA, I.V. Violência contra mulheres: a experiência de usuárias de um serviço de urgência e emergência de Salvador, Bahia, Brasil. Cad. Saude Publica, v.19. supl.2, p.263-72, 2003.

SOARES, B.M. Mulheres invisíveis: violência familiar e formações subjetivas. 1997. Tese (Doutorado) - Instituto Universitário de Pesquisas do Rio de Janeiro, Rio de Janeiro. 1997.

SUCUPIRA, A.C. A importância do ensino da relação médico-paciente e das habilidades de comunicação na formação do profissional de saúde. Interface - Comunic., Saude, Educ., v.11, n.23, p.624-7, 2007.

ROSA, R. et al. Violencia: concepto y experiencia entre los académicos de atención en salud. Interface - Comunic., Saude, Educ., v.14, n.32, p.81-90,jan./mar. 2010.

Se desarrolló una investigación descriptiva exploratoria con enfoque cualitativo y cuantitativo, con 175 alumnos del último año de los cursos de Enfermería, Medicina y Odontología, de la Universidad Federal de Santa Catarina. El objetivo fue entender qué definición de violencia tienen estos alumnos, cuales son sus experiencias sobre el tema y que inserción tuvo la temática de la violencia durante su formación académica. Las definiciones están fuertemente vinculadas con una visión técnica que prioriza los daños físicos sufridos por las personas golpeadas. Frente a una situación de violencia los estudiantes reproducen sentimientos de miedo, impotencia, ira e indignación, sin reaccionar al presenciar estos actos; el estudio demostró que los profesionales de salud no identifican situaciones de violencia cuando atienden a las víctimas de manera superficial; y que en la formación académica no se discute el tema suficientemente.

Palabras clave: Violencia. Salud. Educación superior. Entrenamiento profesional. 